\title{
Case Report: Using ultrasound to prevent a broken catheter from migrating to the heart. [version 1; peer review: 2
}

\section{approved]}

\author{
Pieter J. Schraverus (D), Suzanne van Rijswijk, Pieter Roel Tuinman (iD)
}

Department of Intensive Care, Vrije Universiteit Medical Centre, Amsterdam, The Netherlands

V1 First published: 03 May 2017, 6:616

https://doi.org/10.12688/f1000research.11206.1

Latest published: 03 May 2017, 6:616

https://doi.org/10.12688/f1000research.11206.1

\section{Abstract}

Peripheral intravenous (IV) catheters can break off while still in the patient, with possible detrimental effects such as upstream migration to the heart. These catheters have probably been damaged by the needle during a difficult insertion. A peripheral IV catheter was removed in a 90 year old patient and only half of the catheter was retrieved. By using ultrasound examination the remaining part of the IV catheter was identified, and retrieved surgically, before it could migrate towards the heart. This case report suggests that ultrasound should not only be used for difficult placement of a peripheral IV catheter, but can also be used when removal is complicated.

Keywords

broken catheter, ultrasound, echography

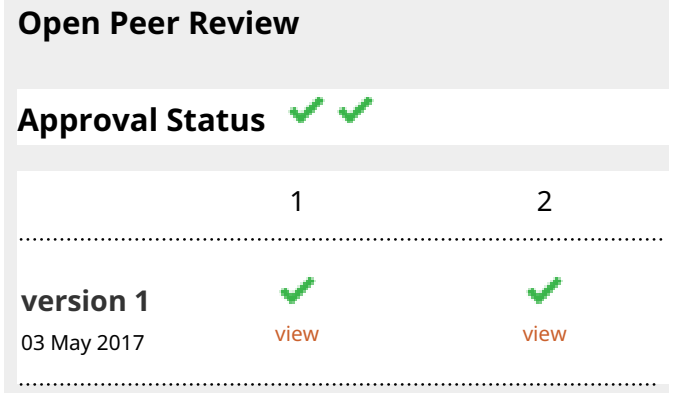

1. Michiel Justinus Blans, Rijnstate Hospital,

Arnhem, The Netherlands

2. Joris Lemson, Radboud University Medical

Centre, Nijmegen, The Netherlands

Any reports and responses or comments on the article can be found at the end of the article.

Corresponding author: Pieter J. Schraverus (schraverus@gmail.com)

Competing interests: No competing interests were disclosed.

Grant information: The author(s) declared that no grants were involved in supporting this work.

Copyright: ( 2017 Schraverus PJ et al. This is an open access article distributed under the terms of the Creative Commons Attribution License, which permits unrestricted use, distribution, and reproduction in any medium, provided the original work is properly cited. Data associated with the article are available under the terms of the Creative Commons Zero "No rights reserved" data waiver (CC0 1.0 Public domain dedication).

How to cite this article: Schraverus PJ, van Rijswijk S and Tuinman PR. Case Report: Using ultrasound to prevent a broken catheter from migrating to the heart. [version 1; peer review: 2 approved] F1000Research 2017, 6:616

https://doi.org/10.12688/f1000research.11206.1

First published: 03 May 2017, 6:616 https://doi.org/10.12688/f1000research.11206.1 


\section{Introduction}

Peripheral intravenous (IV) catheters are given every day to many patients, without much attention given to possible complications. The complications are usually minor, for instance phlebitis or subcutaneous injection of solutions. However, when placement is difficult and the needle of the IV catheter is reinserted for another attempt, the needle can cut the catheter and damage it in such a way that it might break while inside the vein. These fragments can migrate to the right side of the heart, both atrium and ventricle, evidenced by reports in the literature ${ }^{1,2}$.

\section{Case report}

We present the case of a 90 year old caucasian patient where only half of the peripheral IV catheter was retrieved after removal. By using ultrasound the remaining part of the catheter was identified and removed.

The patient was admitted to the hospital with a contained ruptured aneurysm of the abdominal aorta. The patient underwent emergency surgery and an aortic bifurcation prosthesis was placed. According to the anaesthesiologist who cared for the patient, the peripheral catheter was used to administer the anaesthetics and induction of anaesthesia went as planned. After induction, a central venous catheter was placed and the peripheral catheter was no longer used. Post operatively the patient was admitted to the intensive care unit (ICU) where the peripheral catheter was removed and only the proximal half of the catheter came out. We examined the arm but could not palpate the remaining part of the catheter. Ultrasound examination, performed by the ICU resident, showed an echogenic hollow tube (Figure 1), eight centimeters proximal of the insertion site of the catheter. The surgeon made a small incision and the remaining part of the catheter was removed (Figure 2). We were not able to trace the person who placed the IV catheter, to evaluate the technique used.

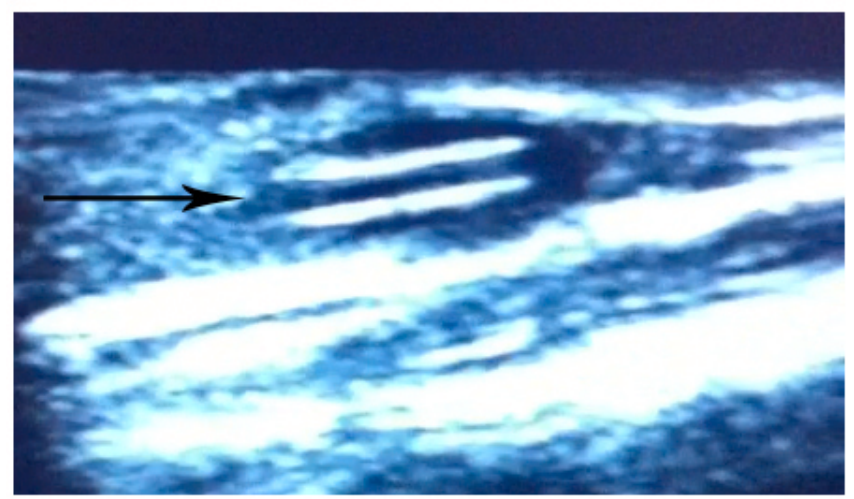

Figure 1. Ultrasound image of the lower arm. The black arrow indicates the broken catheter.

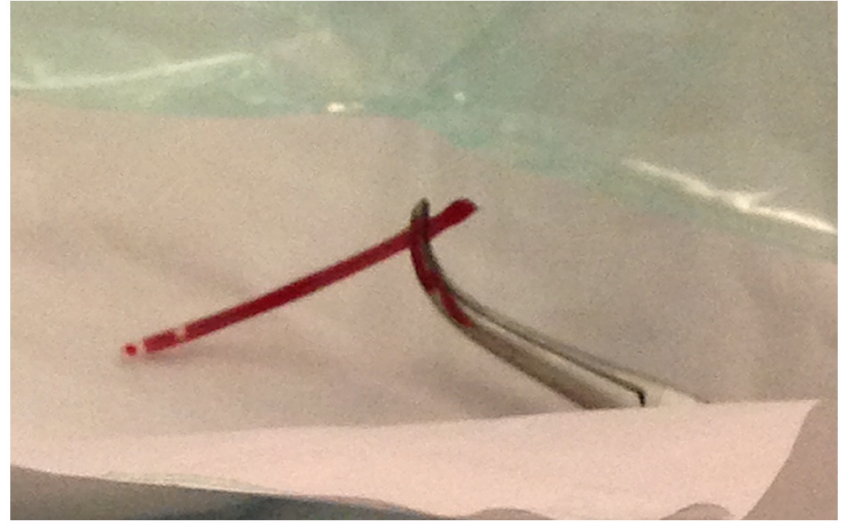

Figure 2. Broken distal part of the peripheral catheter after retrieval.

\section{Discussion}

This case describes the succesful use of ultrasound as a diagnostic tool for difficulties encountered after peripheral IV catheter removal.

We hypothesize that the needle was reinserted in the catheter during placement because placement was difficult. By doing so, the needle may have cut the distal part of the catheter. Reinserting a needle back into a catheter can be dangerous, and there is a risk of damaging the catheter or cutting it off and thereby allowing the free part of the catheter to migrate to the heart, a consequence that could be disastrous and would make removal of the catheter far more difficult ${ }^{3,4}$. The use of ultrasound made a quick diagnosis and enhanced treatment possible, thereby preventing further complications.

\section{Consent}

Written informed consent for publication of clinical details and clinical images was obtained from the patient.

\section{Author contributions}

PJS wrote the manuscript. PRT and SvR revised the manuscript. All authors contributed to design of the manuscript and approved the final version for publication.

\section{Competing interests}

No competing interests were disclosed.

\section{Grant information}

The author(s) declared that no grants were involved in supporting this work. 
1. Van Den Akker-Berman LM, Pinzur S, Aydinalp A, et al:: Uneventful 25-year course of an intracardiac intravenous catheter fragment in the right heart. $J$ Interv Cardiol. 2002; 15(5): 421-3. PubMed Abstract | Publisher Full Text

2. Oto A, Tokgozoglu SL, Oram A, et al:: Late percutaneous extraction of an intracardiac catheter fragment. Jpn Heart J. 1993; 34(1): 117-9.

PubMed Abstract | Publisher Full Text
3. Actis Dato GM, Arslanian A, Di Marzio P, et al:: Posttraumatic and iatrogenic foreign bodies in the heart: report of fourteen cases and review of the literature. J Thorac Cardiovasc Surg. 2003; 126(2): 408-14. PubMed Abstract | Publisher Full Text

4. Sproat IA, Bielke D, Crummy AB, et al.: Transthoracic 2D echocardiographic guidance for percutaneous removal of a nonopaque intracardiac catheter fragment. Cardiovasc Intervent Radiol. 1993; 16(1): 58-60.

PubMed Abstract | Publisher Full Text 


\section{Open Peer Review}

\section{Current Peer Review Status:}

\section{Version 1}

Reviewer Report 06 July 2017

https://doi.org/10.5256/f1000research.12090.r22448

(C) 2017 Lemson J. This is an open access peer review report distributed under the terms of the Creative Commons Attribution License, which permits unrestricted use, distribution, and reproduction in any medium, provided the original work is properly cited.

Joris Lemson

Department of Intensive Care, Radboud University Medical Centre, Nijmegen, The Netherlands

This case report shows the usefulness of ultrasound when a broken intravenous canula had migrated away from the insertion location. The case is adequately described and illustrated and the message is clear. It would be of interest to know if ultrasound devices that are often used at intensive care units are also adequately equipped for searching foreign bodies.

Is the background of the case's history and progression described in sufficient detail? Yes

Are enough details provided of any physical examination and diagnostic tests, treatment given and outcomes?

Yes

Is sufficient discussion included of the importance of the findings and their relevance to future understanding of disease processes, diagnosis or treatment?

Yes

Is the case presented with sufficient detail to be useful for other practitioners? Yes

Competing Interests: No competing interests were disclosed.

I confirm that I have read this submission and believe that I have an appropriate level of expertise to confirm that it is of an acceptable scientific standard.

Reviewer Report 08 May 2017

https://doi.org/10.5256/f1000research.12090.r22447 
(c) 2017 Blans M. This is an open access peer review report distributed under the terms of the Creative Commons Attribution License, which permits unrestricted use, distribution, and reproduction in any medium, provided the original work is properly cited.

\section{Michiel Justinus Blans}

Department of Internal Medicine and Intensive Care, Rijnstate Hospital, Arnhem, The Netherlands

This case report shows that ultrasound can also be used for the described indication. It is well structured and the photo material is clearly showing the described content. Being a short case report no literature review is needed. It is important that modern doctors learn to use all possible aspects of point-of-care ultrasound (as briefly stated, also for the insertion of iv catheters).

Is the background of the case's history and progression described in sufficient detail? Yes

Are enough details provided of any physical examination and diagnostic tests, treatment given and outcomes?

Yes

Is sufficient discussion included of the importance of the findings and their relevance to future understanding of disease processes, diagnosis or treatment?

Yes

Is the case presented with sufficient detail to be useful for other practitioners?

Yes

Competing Interests: No competing interests were disclosed.

I confirm that I have read this submission and believe that I have an appropriate level of expertise to confirm that it is of an acceptable scientific standard. 
The benefits of publishing with F1000Research:

- Your article is published within days, with no editorial bias

- You can publish traditional articles, null/negative results, case reports, data notes and more

- The peer review process is transparent and collaborative

- Your article is indexed in PubMed after passing peer review

- Dedicated customer support at every stage

For pre-submission enquiries, contact research@f1000.com 